\title{
Development and in vitro Evaluation of Pulsatile Drug Delivery System of Enalapril Maleate
}

\author{
Sumaiya Mehjabin Tosha, Ashima Aziz, Sharmin Jahan Chisty, Md. Asaduzzaman and \\ Mohiuddin Ahmed Bhuiyan
}

\begin{abstract}
Pharmaceutical Technology Research Laboratory, Department of Pharmacy, University of Asia Pacific, Dhanmondi, Dhaka-1209, Bangladesh
\end{abstract}

Received: November 20, 2014; Accepted: January 30, 2015

\begin{abstract}
Pulsatile drug delivery of enalapril maleate is one such system that, by delivering drug at the right time, right place and in right amounts, holds good promises of benefit to the patients suffering from hypertension. The basic design involves the preparation of cross linked hard gelatin capsules using formaldehyde. Then the drug diluent mixtures were prepared and loaded which was separated by using hydrogel plug of polymers of different grades such as HPMC 50 cps, HPMC 100 cps, HPMC K4M, HPMC K15M, HPMC K100M, xanthan gum, carbopol 971 and sodium $\mathrm{CMC}$ at different amount $(100$ and $120 \mathrm{mg}$ ). Prepared formulations were subjected to evaluation of various physical parameters and in vitro drug release studies. Dissolution tests were performed using the USP type I basket method at $50 \mathrm{rpm}$ in 6.8 phosphate buffer. From the in vitro dissolution studies it was found that by increasing the amount of polymers, release rate was decreased. Here, $100 \mathrm{mg}$ of HPMC K100M showed $80 \%$ drug release in 8 hours whereas $120 \mathrm{mg}$ showed $78.87 \%$ drug release in 10 hours. Similar decrease in the release rates were found with the increase of other polymers used in this study. The release data was fitted to various mathematical models such as zero order, first order, Higuchi, Korsmeyer Peppas and Hixson Crowell cube root law. The drug release follows mixed order kinetics and mechanism was found to be non-Fickian diffusion.
\end{abstract}

Key words: Pulsatile drug delivery, enalapril maleate, cross-linked hard gelatin capsule, polymer plug.

\section{Introduction}

Over the few decades, advances in research bring both commercial and therapeutic values to health care products. Novel delivery systems work on various principles by providing variable/constant drug amounts over a particular time period in our body based on the fact that physiologic parameters display constancy over a time (Stubbe et al., 2004). However, a new concept which believes this popular belief, termed as chronotherapy has been introduced. Chronotherapeutics refers to a clinical practice of synchronizing drug delivery in a manner consistent with the body's circadian rhythm including disease states to produce maximum health benefit and minimum harmful effects. Particular rhythms in the onset and extent of symptoms were observed in diseases such as, bronchial asthma, myocardial infarction, angina pectoris, rheumatic disease, ulcer, diabetes, attention deficit syndrome, hypercholesterolemia, and hypertension
(Lemmer, 1999). All these acted as a push for the development of pulsatile drug delivery systems. In these systems, there is rapid and transient release of a certain amount of drug molecules within a short time period immediately after a predetermined lag time (Survase and Kumar, 2007). The pulsatile release of an active agent is desirable when treating diseases that require drug delivery in a manner to maintain therapeutic levels albeit circadian rhythms.

Enalapril maleate is the maleate salt of enalapril, the ethyl ester of a long-acting angiotensin converting enzyme inhibitor, enalaprilat. As a prodrug, enalapril is metabolised in vivo to the active form enalaprilat by carboxylesterase (Thomsen et al., 2014). It inhibits angiotensin-converting enzyme (ACE) in human subjects and animals. ACE is a peptidyl dipeptidase that catalyzes the conversion of angiotensin I to the vasoconstrictor substance, angiotensin II. Angiotensin II also stimulates

Correspondence to: Mohiuddin Ahmed Bhuiyan; E-mail: mohiuddin@uap-bd.edu 
aldosterone secretion by the adrenal cortex. The beneficial effects of enalapril in hypertension and heart failure appear to result primarily from suppression of the reninangiotensin-aldosterone system. Inhibition of ACE results in decreased plasma angiotensin II, which leads to decreased vasopressor activity and decreased aldosterone secretion. Enalapril has been shown to lower the death rate in systolic heart failure (John and McMurray, 2010).

Severity of disease like hypertension is time dependent. Sharp increase in attack during early morning hours demands supplement of drug at particular time rather than maintaining constant plasma drug level. A drug delivery system administered at bedtime, but releasing drug as a burst after the time of administration (during morning hours), would be ideal in this case. The present study was designed with a view to develop a formulation for anti-hypertensive drug, enalapril maleate in the mechanism of pulsatile delivery in capsule form which will be a stable and cost effective capsule.

\section{Materials and Methods}

Drugs and chemicals: Enalapril maleate was obtained as a gift from Eskayef Bangladesh Limited. Lactose, avicel, polymer (hydroxypropyl methyl cellulose, methocel, carbopol or other polymer), potassium dihydrogen phosphate, sodium hydroxide, formaldehyde, potassium permanganate etc. were purchased from the local market. The empty capsule shells of size " 0 " were also obtained from Eskayef Bangladesh Limited.
Glassware and equipment: Volumetric flask, test tube, spatula, pipette, funnel, glass rod, syringe, beaker, etc. were used in the study. Electronic balance, vortex mixer, sonicator, $\mathrm{pH}$ meter, dissolution test apparatus, UV-spectrophotometer etc. were used in different steps of the study.

Formaldehyde treated cross-linked gelatin capsule: 25 hard gelatin capsule shells of size "0" were taken and their bodies were separated from the cap. These bodies were put on a wire mesh. $25 \mathrm{ml}$ of $37 \% \mathrm{v} / \mathrm{v}$ of formaldehyde solution was taken in a small beaker. $2.5 \mathrm{~g}$ of potassium permanganate was added into the formaldehyde. This beaker was placed inside the dessicator. Then the wire mesh along with the capsule bodies was kept inside the dessicator and it was closed and sealed. The capsule body reacted with the formaldehyde vapor for 4 hours. After that they were removed and kept on a filter paper and dried in open air for the next 48 hours to make sure that the formaldehyde residues were removed. The capsule bodies were then kept in an airtight container for further use (Ashwini and Ahmed, 2013).

Formulation of the pulsatile capsules: For one capsule $20 \mathrm{mg}$ of enalapril maleate and $130 \mathrm{mg}$ lactose were accurately weighed and taken in a mortar. Enalapril maleate and lactose were properly mixed for about 15 minutes. Different formulations were prepared using the polymers as hydrogel plugs. The formulations are given in Table 1.

Table 1. Different formulation composition.

\begin{tabular}{lllcc}
\hline Formulation Code & Polymer & Grades & $\begin{array}{c}\text { Drug lactose mixture (Each layer } \\
\text { contains half of the following) }\end{array}$ & $\begin{array}{c}\text { Amount of polymer used } \\
\text { to form each plug }\end{array}$ \\
\hline F-1 & HPMC & $50 \mathrm{cps}$ & $150 \mathrm{mg}$ & $100 \mathrm{mg}$ \\
F-2 & HPMC & $100 \mathrm{cps}$ & $150 \mathrm{mg}$ & $100 \mathrm{mg}$ \\
F-3 & KPMC & $150 \mathrm{mg}$ & $100 \mathrm{mg}$ \\
F-4 & HPMC & K15M & $150 \mathrm{mg}$ & $100 \mathrm{mg}$ \\
F-5 & HPMC & K100M & $150 \mathrm{mg}$ & $100 \mathrm{mg}$ \\
F-6 & Carbopol & 971 & $150 \mathrm{mg}$ & $100 \mathrm{mg}$ \\
F-7 & Xanthan gum & Nil & $150 \mathrm{mg}$ & $100 \mathrm{mg}$ \\
F-8 & Sodium CMC & Nil & $150 \mathrm{mg}$ & $100 \mathrm{mg}$ \\
F-9 & HPMC & $50 \mathrm{cps}$ & $150 \mathrm{mg}$ & $120 \mathrm{mg}$ \\
F-10 & HPMC & $100 \mathrm{cps}$ & $150 \mathrm{mg}$ & $120 \mathrm{mg}$ \\
F-11 & HPMC & K4M & $150 \mathrm{mg}$ & $120 \mathrm{mg}$ \\
F-12 & HPMC & K15M & $150 \mathrm{mg}$ & $120 \mathrm{mg}$ \\
F-13 & HPMC & K100M & $150 \mathrm{mg}$ & $120 \mathrm{mg}$ \\
F-14 & Carbopol & 971 & $150 \mathrm{mg}$ & $120 \mathrm{mg}$ \\
F-15 & Xanthan gum & Nil & $150 \mathrm{mg}$ & $120 \mathrm{mg}$ \\
F-16 & Sodium CMC & Nil & $150 \mathrm{mg}$ & $120 \mathrm{mg}$ \\
\hline
\end{tabular}


Filling of capsules: Hard gelatin capsules of size ' 0 ' were taken. Treated body and untreated caps were used for filling purpose. Six capsules for each formulation were prepared manually by the following procedure:

The cap was separated from body manually by hand. The drug lactose mixture $(75 \mathrm{mg}$ ) that was equivalent to $10 \mathrm{mg}$ dose of enalapril maleate was filled into the empty capsule body forming the second dose of the medication. Then different amounts of polymers mentioned in the table was placed just above the second dose and lightly pressed with a glass plunger. In the same manner the first dose of same quantity followed by polymer layer was filled in the same capsule body above the previous layers. Then the cap was joined with the body and stored into an air tight container for further use.

Evaluation of formaldehyde treated capsules: Different types of physical and chemical tests were carried out for treated and untreated capsules. Properties like shape, stickiness, color, odor etc. were checked visually. Length, diameter (both external and internal) and thickness was measured with the help of a vernier caliper (Khan et al., 2011).

Qualitative test for free formaldehyde: At first $20 \mu \mathrm{g} / \mathrm{ml}$ formaldehyde solution was prepared as standard. Twenty five formaldehyde treated bodies were then cut into small pieces and put into a beaker. $40 \mathrm{ml}$ distilled water was added to it and was stirred for $1 \mathrm{hr}$ with a magnetic stirrer to solubilize the free formaldehyde. The solution was filtered into a $50 \mathrm{ml}$ volumetric flask, washed with distilled water and volume was made up to $50 \mathrm{ml}$ with washings. $4 \mathrm{ml}$ of water and $5 \mathrm{ml}$ of acetyl acetone solution were added to $1 \mathrm{ml}$ sample solution in a test tube which was placed in a water bath at $40^{\circ} \mathrm{C}$ for $40 \mathrm{~min}$. At the same time reference solution was placed in the same manner using $1 \mathrm{ml}$ of standard formaldehyde solution. The sample solution was not more intensely colored than the reference solution which indicates that less than $20 \mu \mathrm{g} / \mathrm{ml}$ of free formaldehyde was present in 25 capsule bodies (Khan et al., 2011).

Evaluation of modified pulsincap: Dissolution studies were carried out by using USP I dissolution test apparatus by rotating basket method in different media. During the experiment $\mathrm{pH} 1.2$ medium was first used for 2 hours (since the average gastric emptying time is $2 \mathrm{hrs}$ ) and then the media was removed and a new media of $\mathrm{pH} 6.8$ was added and the procedure continued for the next 10 hours. The amount of media in each time was $900 \mathrm{ml}$. To avoid floating the capsules were placed within baskets. The procedure was maintained at $37 \pm 0.5^{\circ} \mathrm{C}$ and the rotation speed of the basket was $50 \mathrm{rpm}$. Ten milliliters of sample were withdrawn from the dissolution media at predetermined intervals. Same amount of fresh buffer was replaced during each withdrawal. The absorbance was measured at $206 \mathrm{~nm}$ by UV absorption spectroscopy. The data obtained was fitted to various mathematical models such as zero order, first order, Higuchi, Korsmeyer Peppas and Hixson Crowell cube root law to understand the release mechanism.

\section{Results and Discussion}

Pulsincap of enalapril maleate was prepared manually by using various polymers. According to the physical parameters in Table 2 the length of the body of the capsule was found to be 18.2 and $18.3 \mathrm{~mm}$ for untreated and treated capsules respectively. The external diameter was found to be 6.7 and $7.0 \mathrm{~mm}$ for untreated and treated capsules respectively. The thickness of the capsule was found to be in the range of $0.11-0.13 \mathrm{~mm}$. The formaldehyde treated capsules were found to be slightly thicker, as a result they displayed much better sustained release activity compared to an untreated capsule. Average weight of empty capsules was found in the range of 93.3$93.6 \mathrm{mg}$. Treatment did not influence the average capsule weight significantly. Untreated capsule body and cap was dissolved within 15 minutes. On the other hand during the dissolution of treated capsule it was been seen that the cap dissolved within 15 minutes but the treated body remained intact. FTIR studies indicate that drug and polymer did not have any chemical or physical interaction.

From the zero order release kinetics of formulations $100 \mathrm{mg}$ of HPMC $50 \mathrm{cps}$ (F-1) showed $98.92 \%$ drug release in $10 \mathrm{hr}$ whereas $120 \mathrm{mg}$ (F-9) showed 92.85\% drug release in $10 \mathrm{hr}$. In case of HPMC $100 \mathrm{cps}$ (F-2) 100 $\mathrm{mg}$ and (F-10) $120 \mathrm{mg}$, drug release rate were $90.15 \%$ in $8 \mathrm{hrs}$ and $90.84 \%$ in $10 \mathrm{hrs}$ respectively. In case of HPMC $\mathrm{K} 4 \mathrm{M}$ drug release rate were $89.95 \%$ in $9 \mathrm{hrs}, 89.01 \%$ in $10 \mathrm{hrs}$ for (F-3) 100mg, (F-11) $120 \mathrm{mg}$ respectively. In case of HPMC K15M (F-4) $100 \mathrm{mg}$, (F-12) $120 \mathrm{mg}$ drug release rate were $88.83 \%$ in $9 \mathrm{hrs}$ and $82.12 \%$ in $10 \mathrm{hrs}$ respectively. In case of HPMC K100M (F-5) $100 \mathrm{mg}$ and 
(F-13)100 mg, drug release rate were $80 \%$ in $8 \mathrm{hrs}$ and $78.87 \%$ in $10 \mathrm{hrs}$ respectively. $100 \mathrm{mg}$ of Carbopol 971 (F-6) showed $91.05 \%$ drug release in 8 hrs and (F-14) 120 $\mathrm{mg}$ showed $85.68 \%$ drug release in $10 \mathrm{hrs}$. In case of Xanthan Gum (F-7) $100 \mathrm{mg}$ and (F-14) $120 \mathrm{mg}$, drug release rate were $92.396 \%$ in $9 \mathrm{hrs}$ and $90.27 \%$ in $10 \mathrm{hrs}$ respectively. $100 \mathrm{mg}$ of sodium CMC (F-8) showed $93.53 \%$ drug release in $7 \mathrm{hrs} \mathrm{(F-16)} \mathrm{and} 120 \mathrm{mg}$ showed $91.59 \%$ drug release in $10 \mathrm{hrs}$. From the in vitro dissolution studies it was found that by increasing the amount and/ viscosity of polymers, release rate was decreased.
It was observed from Table 3 that most of the formulations followed Korsmeyer Peppas equation and few formulations followed first order release kinetics. The in vitro data was also subjected to Hixon Crowell and Higuchi model. The ' $n$ ' values from the Korsmeyer Peppas plots concluded that all the formulations followed Super case II transport. Case II generally refers to erosion of polymeric chain and anomalous transport (non-fickian) which refers to a combination of both diffusion and erosion controlled drug release.

Table 2. Physical characteristics of empty capsule shells with or without treatment.

\begin{tabular}{cccccccc}
\hline \multirow{2}{*}{$\begin{array}{c}\text { Type of } \\
\text { capsules }\end{array}$} & \multicolumn{2}{c}{ Length $(\mathrm{mm})$} & \multicolumn{2}{c}{ External diameter $(\mathrm{mm})$} & \multicolumn{2}{c}{ Thickness $(\mathrm{mm})$} & \multicolumn{2}{c}{$\begin{array}{c}\text { Weight of empty } \\
\text { capsule }(\mathrm{mg})\end{array}$} \\
\cline { 2 - 6 } & Cap & Body & Cap & Body & Cap & Body & \\
\hline Untreated & $10.9 \pm 0.2$ & $18.2 \pm 0.2$ & $7.5 \pm 0.2$ & $6.7 \pm 0.3$ & $0.1 \pm 0.0$ & $0.1 \pm 0.0$ & $93.3 \pm 1.8$ \\
& & $18.3 \pm 0.1$ & - & $7.0 \pm 0.1$ & - & $0.1 \pm 0.0$ & $93.6 \pm 1.9$ \\
$\begin{array}{c}\text { Formalin } \\
\text { Treated }\end{array}$ & - & & & & & & \\
\hline
\end{tabular}

Table 3. Interpretation of release rate constants and $\mathbf{R}^{2}$ values for different release kinetics.

\begin{tabular}{lccccccccccc}
\hline \multirow{2}{*}{ No } & \multicolumn{2}{c}{ Zero Order } & \multicolumn{2}{c}{ First Order } & \multicolumn{2}{c}{ Higuchi } & \multicolumn{2}{c}{ Korsmeyer } & \multicolumn{2}{c}{ Hixson Crowell } \\
\cline { 2 - 11 } & $\mathrm{R}^{2}$ & $\mathrm{~K}_{0}$ & $\mathrm{R}^{2}$ & $\mathrm{~K}_{1}$ & $\mathrm{R}^{2}$ & $\mathrm{~K} \mathrm{H}$ & $\mathrm{R}^{2}$ & $\mathrm{n}$ & $\mathrm{R}^{2}$ & $\mathrm{~K}_{\mathrm{HC}}$ \\
\hline F-1 & 0.859 & 10.79 & 0.984 & -0.198 & 0.936 & 40.37 & 0.931 & 1.251 & 0.976 & -0.390 \\
F-2 & 0.946 & 10.13 & 0.977 & -0.131 & 0.982 & 37.00 & 0.970 & 1.140 & 0.991 & -0.307 \\
F-3 & 0.972 & 9.618 & 0.915 & -0.110 & 0.952 & 34.09 & 0.967 & 1.109 & 0.958 & -0.270 \\
F-4 & 0.973 & 9.922 & 0.952 & -0.102 & 0.945 & 35.02 & 0.906 & 1.037 & 0.979 & -0.263 \\
F-5 & 0.928 & 8.620 & 0.976 & -0.083 & 0.950 & 31.26 & 0.939 & 1.297 & 0.966 & -0.222 \\
F-6 & 0.892 & 10.14 & 0.955 & -0.167 & 0.970 & 37.91 & 0.966 & 1.246 & 0.987 & -0.346 \\
F-7 & 0.976 & 10.35 & 0.892 & -0.132 & 0.946 & 36.54 & 0.953 & 1.070 & 0.963 & -0.306 \\
F-8 & 0.955 & 11.32 & 0.855 & -0.221 & 0.931 & 40.08 & 0.970 & 1.125 & 0.962 & -0.405 \\
F-9 & 0.949 & 9.459 & 0.970 & -0.115 & 0.937 & 33.68 & 0.897 & 1.381 & 0.972 & -0.280 \\
F-10 & 0.943 & 9.541 & 0.965 & -0.107 & 0.941 & 34.15 & 0.968 & 1.272 & 0.965 & -0.268 \\
F-11 & 0.964 & 9.543 & 0.942 & -0.097 & 0.915 & 33.31 & 0.954 & 1.11 & 0.956 & -0.254 \\
F-12 & 0.958 & 9.246 & 0.976 & -0.080 & 0.941 & 32.84 & 0.968 & 0.933 & 0.949 & -0.280 \\
F-13 & 0.958 & 8.137 & 0.912 & -0.067 & 0.874 & 27.85 & 0.929 & 1.070 & 0.930 & -0.191 \\
F-14 & 0.969 & 9.100 & 0.905 & -0.083 & 0.912 & 31.64 & 0.940 & 0.943 & 0.937 & -0.225 \\
F-15 & 0.981 & 9.444 & 0.935 & -0.093 & 0.940 & 33.13 & 0.980 & 0.967 & 0.967 & -0.244 \\
F-16 & 0.956 & 10.11 & 0.935 & -0.112 & 0.917 & 35.49 & 0.973 & 1.068 & 0.949 & -0.280 \\
\hline
\end{tabular}


A1)

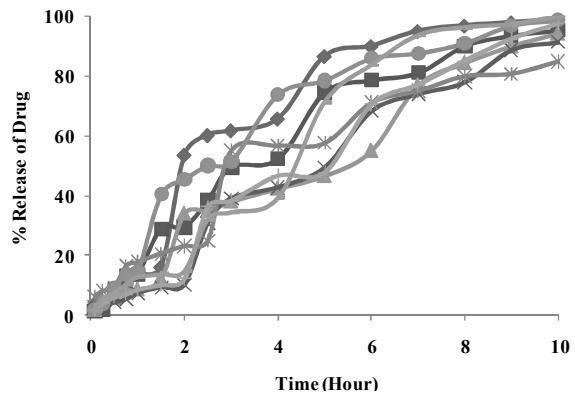

B1)

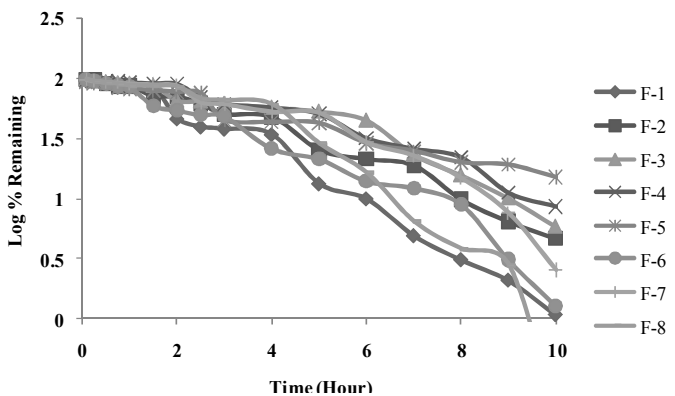

C1)

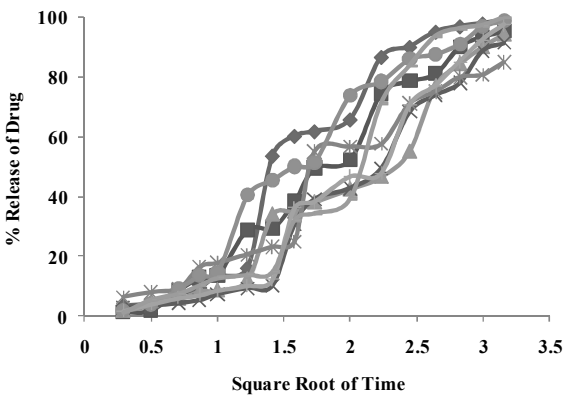

D1)

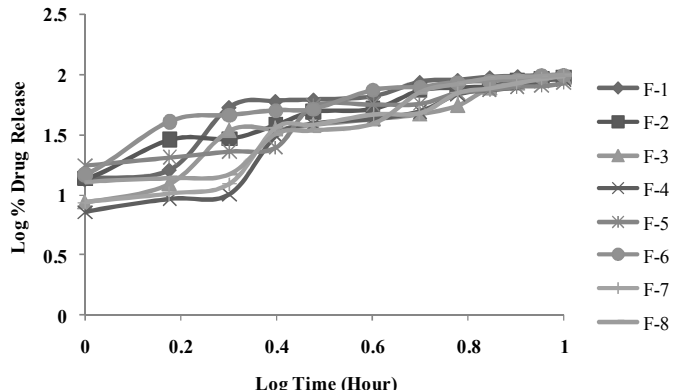

E1)

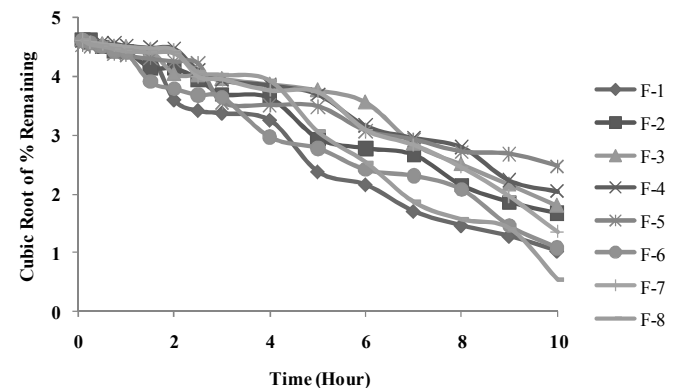

A2)

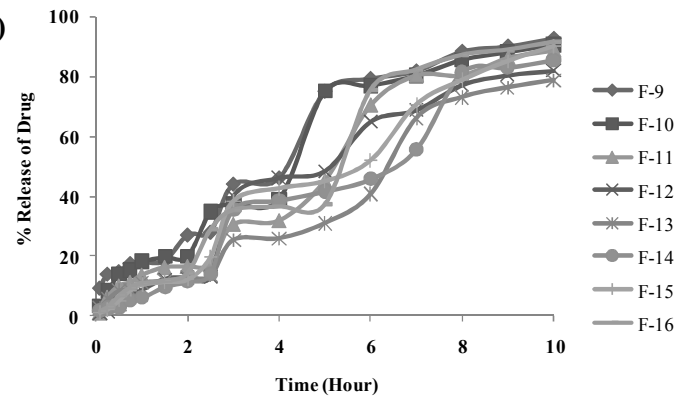

B2)

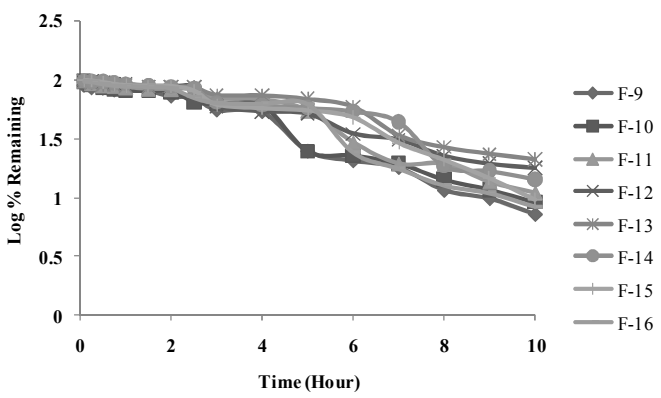

C2)

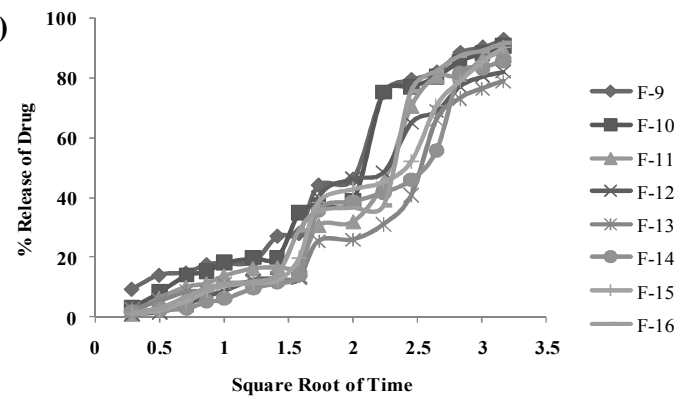

D2)

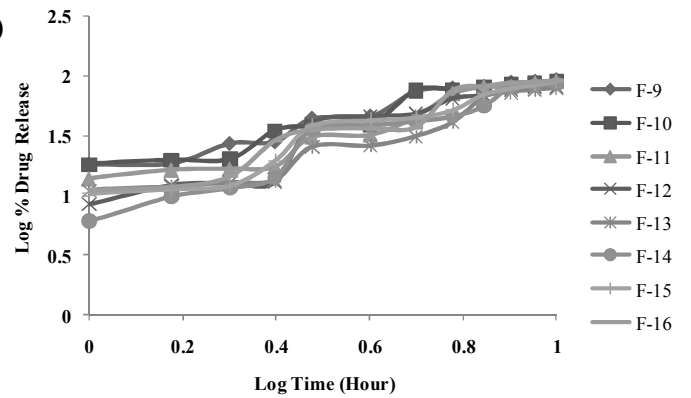

E2)

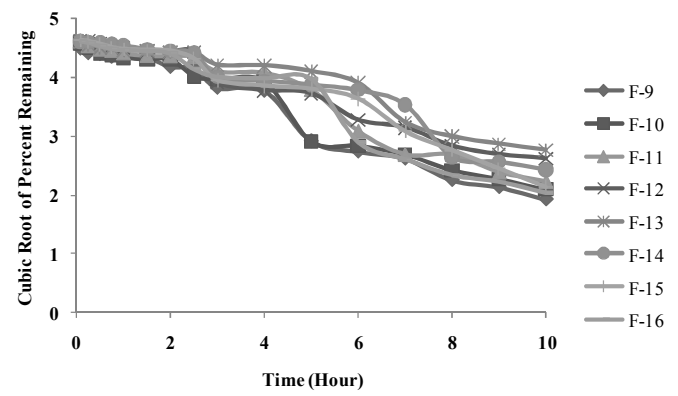

Figure 1. Zero order release kinetics (A), first order release kinetics. (B), Higuchi release kinetics (C), Korsmeyer release kinetics (D) and Hixson-Crowell release kinetics (E) of formulation F1-F8 and F9- F16 containing different polymer grades used in the study with an amount of $100 \mathrm{mg}(1)$ and $120 \mathrm{mg}(2)$ respectively/ 


\section{Conclusion}

Pulsatile drug delivery system of enalapril maleate intends to release drugs on a programmed pattern at specific time and specific site as per the pathophysiological need of the disease. The results show that after a lag time the first dose of drug releases. The amount and type of polymer decides the lag time. This pulsatile system tried to be designed in such a way that a complete and rapid drug release is achieved after the lag time so as to match body's circadian rhythms with the release of drug which increases the efficacy and safety of drugs by proportioning their peak plasma concentrations during the 24 hours in synchrony with biological rhythm. Selection of this dosage form should be taken into considerations on the basis of application range (e.g. targeted drugs of different physico-chemical properties), ease of manufacturing, cost-effectiveness, and flexibility in the pharmacokinetic profile. It should be pointed that these drug delivery systems are still in the early developmental stage and much research will have to be conducted for such systems which improved patient outcome and optimize disease management in the future.

\section{Acknowledgement}

The authors would like to acknowledge the support received from the Eskayef Bangladesh Ltd.

\section{Conflict of Interest}

The authors have no conflict of interest.

\section{References}

Ashwini, M.S. and Ahmed, M.G. 2013. Design and evaluation of pulsatile drug delivery system of losartan potassium. Dha. Univ. J. Pharm. Sci. 12, 87-91.

John, J.V. and McMurray, M.D. 2010. Systolic heart failure. The New Eng. J. Med. 362, 228-238.

Khan, A.W., Mohammad, G.A. and Ramesh, B. 2011. Novel sustained release pulsatile capsules of terbutaline sulphate. Res. J. Pharm. Tech. 10, 551-558.

Lemmer, B. 1999. Chronopharmacokinetics: implications for drug treatment. J. Pharm. Pharmacol. 51, 887-890.

Stubbe, B.G., Smedt, S.C. and Demeester, J. 2004. Programmed polymeric devices for pulsed delivery. Pharm. Res. 21, 1732-1740.

Survase, S. and Kumar, N. 2007. Pulsatile drug delivery: current scenario. Cur. Res. Inf. Pharm. Sci. 8, 27-33.

Thomsen, R., Rasmussen, H.B. and Linnet, K., INDICES Consortium. 2014. In vitro drug metabolism by human carboxylesterase 1: focus on angiotensin-converting enzyme inhibitors. Drug Met. Disp. 42, 126-133. 